\title{
EDITORIAL
}

\section{Rehabilitation in COPD patients: evergreen in pneumology and beyond}

\author{
E. Clini* and N. Ambrosino ${ }^{\#, 9}$
}

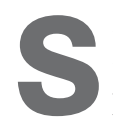
everal studies have shown that pulmonary rehabilitation (PR) has a beneficial effect on symptoms and on health-related quality of life (HRQoL) in stable chronic obstructive pulmonary disease (COPD) patients [1, 2].

The ultimate goal in these patients is to counteract progressive functional limitations following the impairment of the respiratory apparatus, thus allowing a more active lifestyle by interrupting the so called "dyspnoea inactivity vicious circle".

During the 1980s, several randomised controlled trials demonstrated the effectiveness of PR in improving clinical outcomes relevant to a COPD population [3-5], while the 1990s were characterised by major gains obtained in causing physiological training effects [6], and improving dyspnoea [7] as well as HRQoL [8].

At the beginning of the new millenium, the first published randomised controlled trial successfully showed a decrease in healthcare utilisation with PR appropriately delivered to COPD patients [9].

Nowadays, major effort needs to be addressed to the implementation of optimal rehabilitation regimens focused on individual needs, clarifying the effects of different PR components, exercise modalities and feasible settings. Although further research is needed to better understand the ideal components, modalities and settings that enable an optimal individualised rehabilitation process, recent scientific exploration has shown that PR of COPD patients allows for strong arguments in favour of its widespread dissemination. Notwithstanding, the clinical scenario in the COPD population has dramatically changed over recent decades, thus suggesting new approaches and different timing to expand PR intervention.

First, the varying severity and complexity across the COPD categories [10] has led clinical researchers to include different options for training peripheral muscle; thus, although not generalisable, different modalities, such as interval training [11] or supported exercise, have been proposed to include the most disabled individuals [12, 13].

\footnotetext{
*Dept of Oncology, Haematology and Respiratory Diseases, University of Modena and Reggio Emilia, Ospedale Villa Pineta, Pavullo n/F (Modena), ${ }^{*}$ Cardio-Thoracic Dept, Pulmonary Division, University Hospital, Pisa, "Pulmonary Rehabilitation and Weaning Center, Auxilium Vitae, Volterra, Italy.

CORRESPONDENCE: E.M. Clini, University of Modena-Reggio Emilia and Ospedale Villa Pineta, Via Gaiato 127, 41060 Pavullo n/F (Modena), Italy. E-mail: enrico.clini@unimore.it
}

Secondly, recent studies in the COPD population have shown that PR following acute exacerbations requiring hospital admission is associated with clinically meaningful improvement in exercise tolerance, and that deterioration in muscle performance after exacerbation may be prevented by peripheral training application during acute care [14]. This might be further translated into a substantial reduction of healthcare resource consumption in the follow-up of these patients [15].

Early management with PR in the acute COPD population has some practical consequences for hospital management, beyond the usual medical therapy. Indeed, it restores the importance of nonpharmacological therapy at the earliest onset of disability and emphasises the role of physical therapies in the acute setting [16].

The latter problem also invites clinicians to give close attention to those very severe patients admitted to critical care, who are invariably dealing with a prolonged stay in bed and/ or difficult weaning, including opening tracheostomy. The general scope of a physiotherapy programme in a respiratory intensive care unit is to apply advanced, cost-effective therapeutic modalities to decrease the patient's dependency on the ventilator, to spare and eventually to improve the residual functions, to prevent the need for repeat hospitalisations, and to improve the patient's HRQoL. In other words, the aim of this programme is to enhance the patient's overall functional capacity and to restore his/her respiratory and physical independence, thus decreasing the risks of bed lying-associated complications [17]. The earlier physiotherapy of a ventilated patient is started, the greater its effect on avoiding later consequences, such as weaning delay, limited mobility or, even worse, total dependency on a ventilator in the long term.

Finally, and not least, the new COPD population presents some features that deserve further attention. The probability of patients obtaining substantial benefit from PR programmes may also depend on several characteristics of the patients related to their different phenotypes, different complexity and disability, the associated social and familial environment, etc., which may influence and predict a priori the likely outcomes $[18,19]$. This may obviously translate into the need for a better and more accurate definition of candidates for PR, which in turn may lead to a better allocation of resources, due to the real worldwide restrictions in healthcare systems.

This issue of the European Respiratory Journal contains the first review article of a new series, Novelties in Pulmonary Rehabilitation, dealing with all these innovative aspects 
TABLE 1 Invited reviews in the Novelties in Pulmonary Rehabilitation series

\begin{tabular}{|c|c|}
\hline Subject [ref.] & Invited authors \\
\hline Rehabilitation and acute exacerbations of COPD [20] & T. Troosters (Catholic University of Leuven, Leuven, Belgium) \\
\hline Strategies of muscle training in very severe COPD patients [21] & $\begin{array}{l}\text { I. Vogiatzis (National and Kapodistrian University of Athens, } \\
\text { Athens, Greece) }\end{array}$ \\
\hline \multirow[t]{3}{*}{ Determinants of success [22] } & R. Garrod (King's College Hospital, London, UK) \\
\hline & M. Malerba (University of Brescia, Brescia, Italy) \\
\hline & E. Crisafulli (University of Modena-Reggio Emilia, Modena, Italy) \\
\hline New tools in pulmonary rehabilitation & $\begin{array}{l}\text { P. Wijkstra (University Medical Centre Groningen, Groningen, The } \\
\text { Netherlands) }\end{array}$ \\
\hline \multirow[t]{2}{*}{ Physiotherapy in the respiratory ICU } & N. Ambrosino (University Hospital Pisa, Pisa, Italy) \\
\hline & E. Clini (Modena, Italy) \\
\hline
\end{tabular}

COPD: chronic obstructive pulmonary disease; ICU: intensive care unit.

associated with the rehabilitation of COPD (table 1) [20]. As the guest editors of these review articles, we have chosen five main topics of interest to bring readers some of the hot topics and/or unanswered questions in this clinical area.

In particular, we expect that these reviews will arouse curiosity in all those professionals who are practically oriented in the field of respiratory medicine.

\section{STATEMENT OF INTEREST}

None declared.

\section{REFERENCES}

1 Nici L, Donner C, Wouters E, et al. American Thoracic Society/ European Respiratory Society statement on pulmonary rehabilitation. Am J Respir Crit Care Med 2006; 173: 1390-1413.

2 Ries AL, Bauldoff GS, Carlin BW, et al. Pulmonary rehabilitation: joint ACCP/AACVPR evidence-based clinical practice guidelines. Chest 2007; 131: Suppl., 4s-42s.

3 Cockcroft AE, Saunders MJ, Berry G. Randomised controlled trial of rehabilitation in chronic respiratory disability. Thorax 1981; 36: 200-203.

4 Booker HA. Exercise training and breathing control in patients with chronic airflow limitation. Physiotherapy 1984; 70: 258-260.

5 Busch AJ, McClements JD. Effects of a supervised home exercise program on patients with severe chronic obstructive pulmonary disease. Phys Ther 1988; 68: 469-474.

6 Casaburi R, Patessio A, Ioli F, et al. Reductions in exercise lactic acidosis and ventilation as a result of exercise training in patients with obstructive lung disease. Am Rev Respir Dis 1991; 143: 9-18.

7 Reardon J, Awad E, Normandin E, et al. The effect of comprehensive outpatient pulmonary rehabilitation on dyspnea. Chest 1994; 105: 1046-1052.

8 Goldstein RS, Gorth EH, Stubbing D, et al. Randomised controlled trial of respiratory rehabilitation. Lancet 1994; 344: 1394-1397.
9 Griffiths TL, Burr ML, Campbell IA, et al. Results at 1-year of outpatient multidisciplinary pulmonary rehabilitation: a randomised controlled trial. Lancet 2000; 355: 362-368.

10 Crisafulli E, Costi S, Luppi F, et al. Role of comorbidities in a cohort of patients with COPD undergoing pulmonary rehabilitation. Thorax 2008; 63: 487-492.

11 Vogiatzis I, Simoes DCM, Stratakos G, et al. Effect of pulmonary rehabilitation on muscle remodelling in cachectic patients with COPD. Eur Respir J 2010; 36: 301-310.

12 Ambrosino N, Strambi S. New strategies to improve exercise tolerance in chronic obstructive pulmonary disease. Eur Respir J 2004; 24: 313-322.

13 Duiverman ML, Wempe JB, Bladder G, et al. Nocturnal noninvasive ventilation in addition to rehabilitation in hypercapnic patients with COPD. Thorax 2008; 63: 1052-1057.

14 Clini EM, Roversi P, Crisafulli E. Early rehabilitation: much better than nothing. Am J Respir Crit Care Med 2010; 181: 1016-1017.

15 Puhan M, Scharplatz M, Troosters T, et al. Pulmonary rehabilitation following exacerbations of chronic obstructive pulmonary disease. Cochrane Database Syst Rev 2009; 21: CD005305.

16 Clini EM, Ambrosino N. Nonpharmacological treatment and relief of symptoms. Eur Respir J 2008; 332: 218-228.

17 Clini E, Ambrosino N. Early physiotherapy in the respiratory intensive care unit. Resp Med 2005; 99: 1096-1104.

18 Sabit R, Griffiths TL, Watkins AJ, et al. Predictors of poor attendance at an outpatient pulmonary rehabilitation programme. Respir Med 2008; 102: 819-824.

19 Garrod R, Marshall J, Barley E, et al. Predictors of success and failure in pulmonary rehabilitation. Eur Respir J 2006; 27: 788-794.

20 Burtin C, Decramer M, Gosselink R, et al. Rehabilitation and acute exacerbations. Eur Respir J 2011; 38: 702-712.

21 Vogiatzis I. Strategies of muscle training in very severe COPD patients. Eur Respir J 2011; [Epub ahead of print DOI: 10.1183/ 09031936.00075011].

22 Garrod R, Malerba M, Crisafulli E. Determinants of success. Eur Respir J 2011; [Epub ahead of print DOI: 10.1183/09031936. 00088611]. 